\title{
Fuel Level Monitoring and Security Warning Tools using IoT for Komatsu Excavator PC200-8M0
}

\author{
Yohanes Acep Nanang Kardana \\ Master of Mechanical Engineering \\ Swiss German University \\ Tangerang City, Indonesia \\ acepnanang@gmail.com \\ Henry Nasution \\ Master of Mechanical Engineering \\ Swiss German University \\ Tangerang City, Indonesia \\ henry.nasution@sgu.ac.id
}

\author{
*Hanny J. Berchmans \\ Master of Mechanical Engineering \\ Swiss German University \\ Tangerang, Indonesia \\ hannyjberchmans2020@gmail.com \\ Dena Hendriana \\ Master of Mechanical Engineering \\ Swiss German University \\ Tangerang City, Indonesia \\ dena.hendriana@sgu.ac.id
}

\author{
1,2 Cuk Supriyadi Ali N \\ ${ }^{2}$ Agency for the Assessment \& \\ Application of Technology (BPPT) \\ Tangerang, Indonesia \\ ${ }^{1}$ Master of Mechanical Engineering \\ Swiss German University \\ Tangerang City, Indonesia \\ cuksupriyadi@gmail.com
}

\begin{abstract}
Komatsu PC200-8M0 excavators operate mostly in the mining and forestry sector that covers a very large land area up to thousands hectares. Operation of this excavator requires a fuel tank for refueling process. In many cases, there were fuel thefts from the fuel tank of this excavator because the excavator were located in remote area. To overcome this problem, it is necessary to develop a fuel monitoring tool that can monitor and send warnings to the excavator owner if there is any fuel access into the excavator fuel tank during the rest time of the excavator. The monitoring tool is developed by using a NODEMCU ESP8266 microcontroller that connected to the internet network so that it will be able to communicate with the Thingspeak webserver. With internet access, the monitoring process can be carried out by using a computer and also smart mobile phone.
\end{abstract}

Keywords-internet of things, NODEMCU ESP8266, excavator, fuel monitoring, fuel security, thingspeak.

\section{INTRODUCTION}

Komatsu PC200-8M0 is one of popular excavator brand in Indonesia that distributed by PT. United Tractors Tbk. It is a 20 tons class excavator for construction, mining and forestry sector (Fig. 1). Generally, construction, mining and forestry sectors cover very large land area (Fig. 2) up to thousands of hectares. Operation of this excavator requires a fuel tank for refueling process. The fuel supply division must contact the operator to find out the amount of fuel in the unit to determine which units must be filled and which units should be prioritized to be filled first.

In addition, there were several cases of fuel theft on heavy equipment, one of which also occurred at Komatsu PC200-8M0. There are two fuel lines that are accessible for fuel theft namely the filling line and the tank sediment disposal line. Theft in large numbers occurs through charging line. The thief needs a hose to take fuel. Thief in small amounts is usually done through a sewer drainage line, this line is a hose with a tap installed under the tank [14].

In this paper, we develop a device that able to monitor the amount of fuel in the tank and an indicator in the drainage tank drain. By using the Internet of Things (IoT) system, data from the devices will be sent in real time to the owner of the excavator/person concerned. This data is also used to turn on the theft alarm on the unit and as data that can be used for fuel management [5].

To test the security system model, some data is needed to determine whether the fuel in fuel tank has been reduced due to theft.
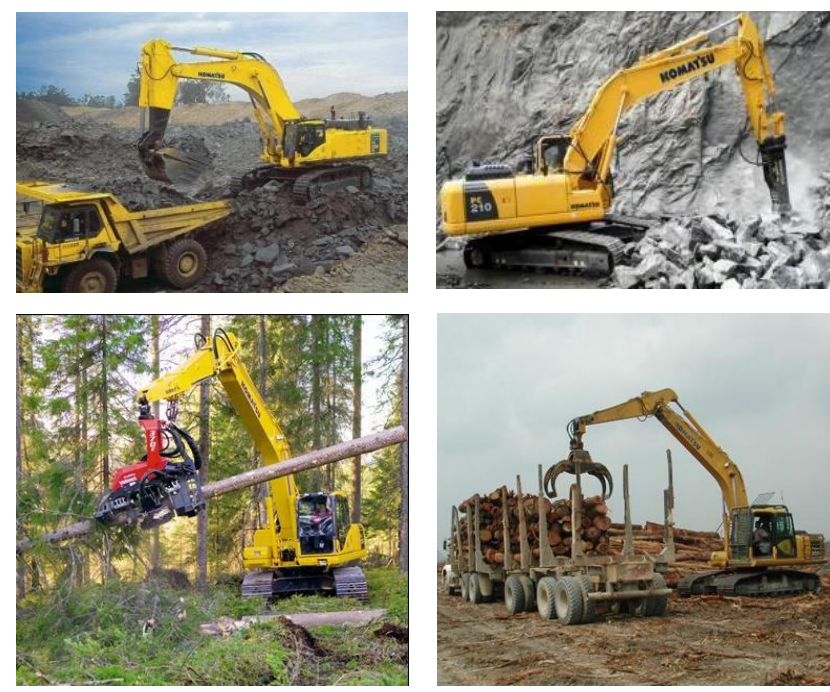

Fig. 1. Excavator in mining and forestry sector. 


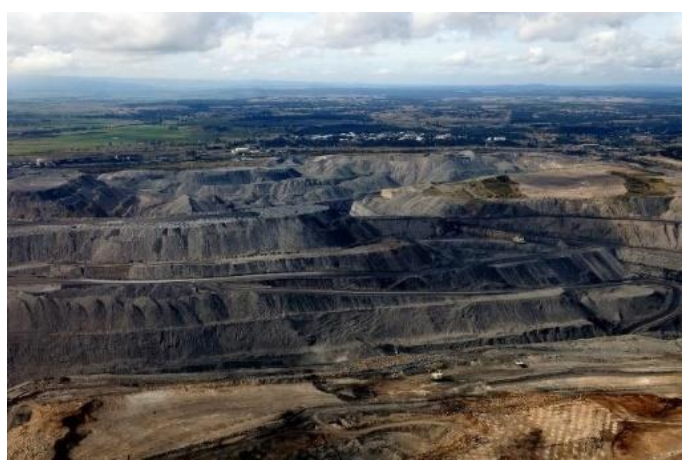

Fig. 2. Large area of mining sector

\section{METHODE}

This tool is developed by using the original data from the actual excavator unit sensors and also utilizing data from some experiments in a fuel test bench.

\section{A. Komatsu Excavator PC200-8MO}

Komatsu PC200-8M0 is one of 20 tons class hydraulic excavator that used at construction, forestry, mining and many others industrial sector in Indonesia. Main component of the excavator is shown a Fig.3 below [1-4].

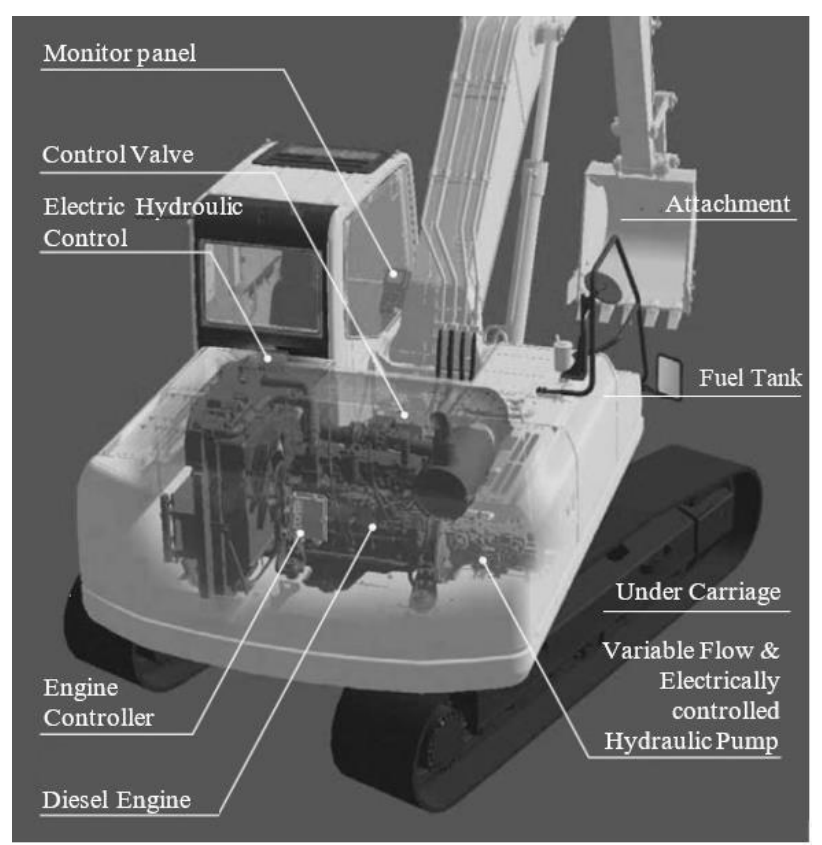

Fig. 3. Komatsu PC200-8M0 Main Component

Excavators are heavy equipment that have the primary function of digging up soil and moving material, but if we attach additional attachments, excavators can do many things such as cutting down trees (industrial forests), breaking rocks, eroding cliffs and even cleaning and deepening rivers.

According to the technical specifications datasheet of this excavator (Fig. 4), the excavator engine has a maximum power of $110 \mathrm{~kW}$ with a minimum fuel consumption of 215 $\mathrm{g}$ fuel consumption if maximum power use is $23.65 \mathrm{l} /$ hour.

\begin{tabular}{|c|c|c|c|}
\hline \multirow{2}{*}{\multicolumn{3}{|c|}{$\begin{array}{l}\text { Machine model } \\
\text { Serial number }\end{array}$}} & \multirow{4}{*}{\begin{tabular}{c|c} 
PC200-8M0 & PC200LC-88M0 \\
400001 and up \\
SAAD 107E-1 \\
4-cycle, water-cooled in-line, direct injection wth \\
turbocharger and air-coled afercooler \\
$6-107 \times 124$ \\
$669\{6.690\}$
\end{tabular}} \\
\hline & & & \\
\hline \multirow{13}{*}{$\begin{array}{l}\text { : } \\
\text { : }\end{array}$} & $\begin{array}{l}\text { Model } \\
\text { Type }\end{array}$ & & \\
\hline & Number of cylinders - bore $\mathrm{x}$ stroke & $\mathrm{mm}$ & \\
\hline & \begin{tabular}{|l} 
Pisition displacementi \\
Rated hosepower
\end{tabular} & & \\
\hline & - SAE J1995 [gross] & & $110\{147\} / 2000(2000)\}$ \\
\hline & $8 \cdot{ }^{-}$ISO 14396 & $\min ^{-1}(\mathrm{pm})$ & $110\{1477 / 2000(2000\}$ \\
\hline & 垔 & $\mathrm{Nm}\{\mathrm{kgm}\} /$ & 6026141450015001 \\
\hline & 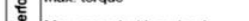 & $\min ^{\prime \prime}(\mathrm{ppm}\}$ & \\
\hline & - Max speed with no load & $\min ^{-1}(\mathrm{rpm}\}$ & $2,060\{2,060\}$ \\
\hline & Min. speed with no load & $\min ^{\prime \prime}$ (rpm) & $1.050\{1.050\}$ \\
\hline & Starting motor & & $24 \mathrm{~V}, 4.5 \mathrm{~kW}$ \\
\hline & Anternator & & $24 \mathrm{~V}, 35 \mathrm{~A}$ \\
\hline & Battery & & $12 \mathrm{~V}, 110 \mathrm{Ah} \times 2$ \\
\hline & \begin{tabular}{|l|} 
Radiator tive \\
\end{tabular} & & CF904 \\
\hline
\end{tabular}

Fig. 4. Engine specification [1-4]

If we convert to liter/hour when it work for maximum power is:

Fuel consumption $=$

$$
\frac{\text { fuel consumption }\left(\frac{g}{k W h}\right) \times \text { maximumpower }(k W h)}{\text { density }\left(\frac{k g}{m^{3}}\right)}
$$

The fuel tank (Fig. 5) used by this excavator is a pressure tank type equipped with a pressure limiting valve. This tank has the following specifications.

$$
\begin{array}{ll}
\text { Maximum Volume } & : 400 \text { liter } \\
\text { Input line } & : 1 \text { input with strainer and lock } \\
\text { Output line } & : 1 \text { Breather line } \\
& 1 \text { main supply line to engine } \\
& 1 \text { return line from engine } \\
& 1 \text { sewage drain line }
\end{array}
$$

Level Sensor $\quad$ : Resistive sensor

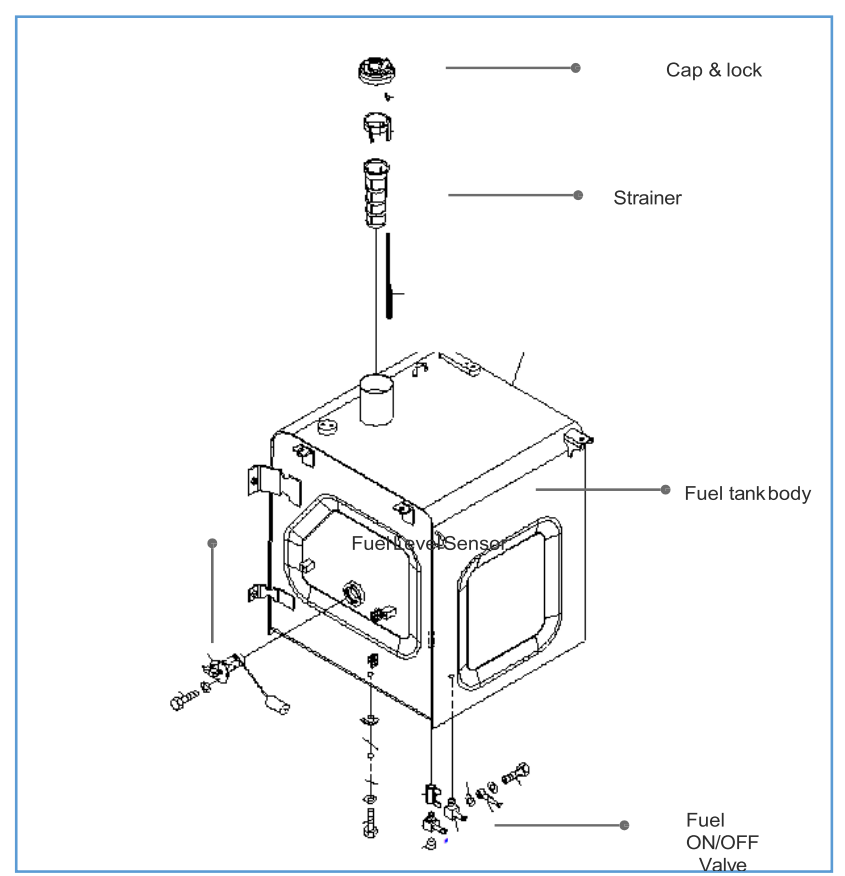

Fig. 5. Fuel tank component [3] 
The total tank capacity is 400 liters, the amount of fuel measured by the sensor is from 41 liters to 300 liters, this is intended so that the tank does not become empty at all. Working voltage from controller are 3.2 Volt and the resistance of the sensor displayed in Fig. 6.

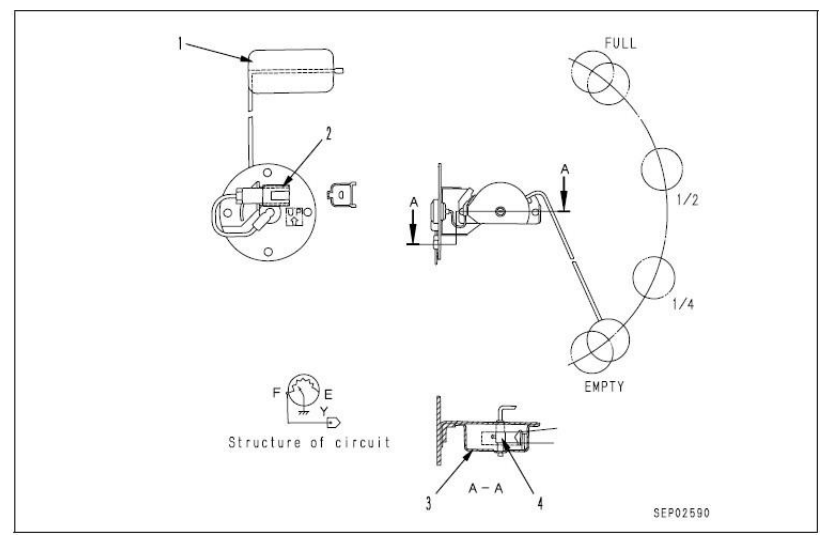

\begin{tabular}{|l|c|c|c|}
\hline \multicolumn{4}{|c|}{ Procedure, measuring location, criteria and remarks } \\
\hline $\begin{array}{l}\text { 1. Turn starting switch to OFF position. } \\
\text { 2. Disconnect connector P21 and connect T-adapters to male side. }\end{array}$ \\
\hline $\begin{array}{c}\text { Between P21 (male) (1) } \\
\text { and ground }\end{array}$ & Fuel level: FULL & Resistance & 7 to $11 \Omega$ \\
\cline { 2 - 4 } & Fuel level: EMPTY & Resistance & 85 to $95 \Omega$ \\
\hline
\end{tabular}

Fig. 6. Fuel level sensor $\&$ short wiring diagram

The original fuel level sensor (Fig. 7) is used for the test bench, the sensor is tested to know its characteristics.

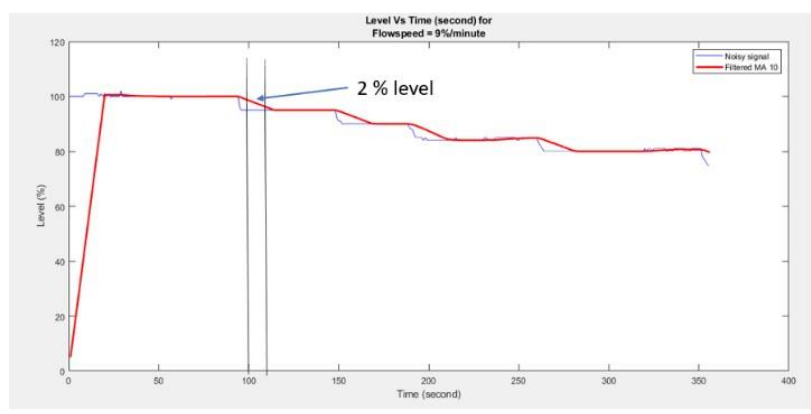

Fig. 7. Fuel level sensor characteristic.

This fuel level sensor has a nonlinear change in resistance to the angle of motion. As shown in the figure above, the curve has $2 \%$ decline in each step.

\section{B. Hardware Design}

In this experiment, real fuel tank was modeled using a plastic box with water as a fuel (Fig. 8). The real time fuel level was measured by level sensor and real time flow volume from fuel tank drain line was be measured by flow sensor, both of data were collected and sent wirelessly to the webserver by using NODEMCU ESP8266 microcontroller [6-8].

Thingspek (Fig. 9) will be use as web server to collect and show the fuel level data. An android mobile application that developed by MIT Application Inventor will be used as a graphic user interface to monitor and send command to NODEMCU ESP8266 microcontroller to turn on the alarm. Real time fuel level data can be used as a reference to choose which excavator priority must be filled in advance. Real time data from flow sensor will be used as signal if the thief occurred [9].

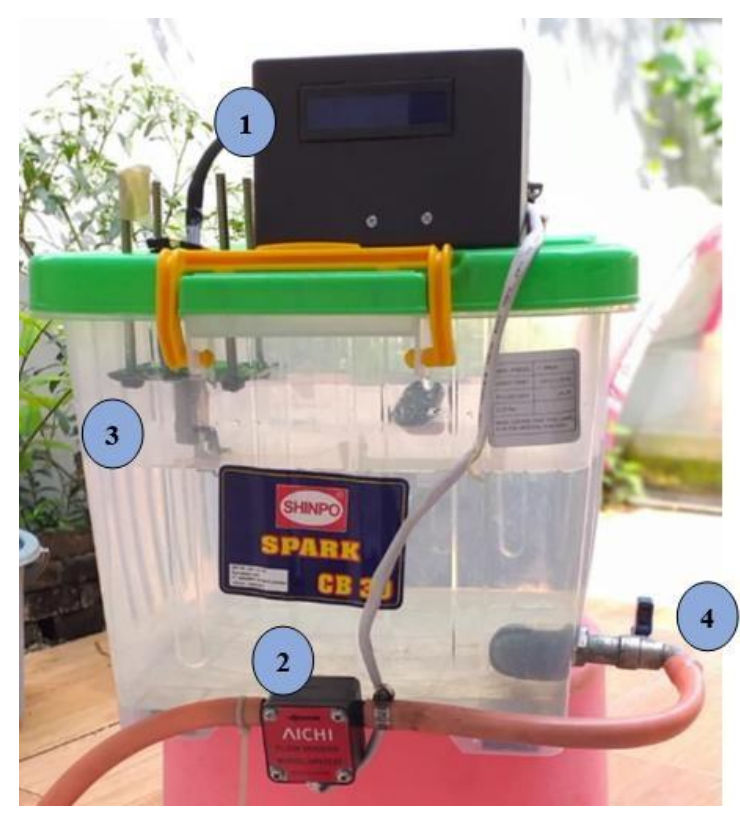

Fig. 8. Fuel tank test bench

1. Controller with LCD and stepdown power supply

2. Flow meter.

3. Level sensor (inside the tank).

4. Drain valve

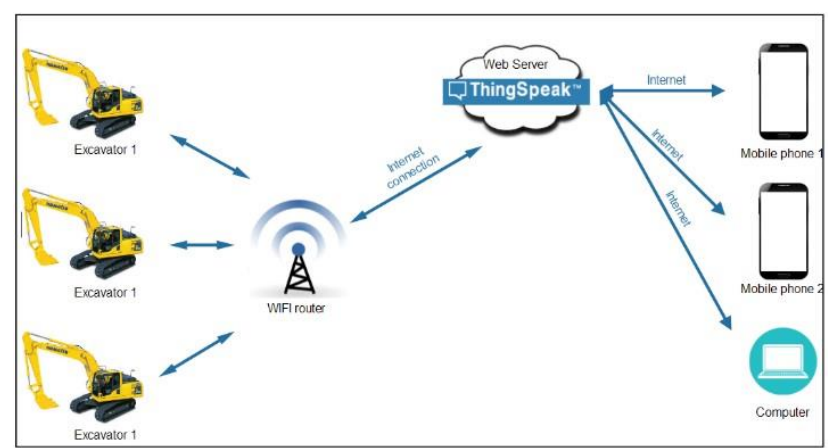

Fig. 9. IoT concept design

\section{Theft Test}

For normal service operation, the fuel data for excavator fuel tank:

1. Maximum operation 23.6 liter per hour..

2. Pre fuel filter volume: 2.5 Liter.

3. Fuel for wash a maintenance component: \pm Max 3 liter (By interview).

\section{RESULT AND DISCUSION}

This tool is designed to be able to do 4 things:

1. Read the fuel level data in the fuel tank for every 1 second, average it and send the data to the server every 10 minutes. 
2. Measure the amount of fuel that out of the sewage drain when a fuel is taken from the channel every 1 second and send the amount released after more than 3 liters to the Thingspeak as a theft alarm.

3. Turn on the alarm whenever a theft occurs with the following parameters.

a. Fuel in the tank decreases by more than a certain volume every 5 minutes.

b. Fuel comes out of the tank through the sewage drain more than 3 liters in one tap opening.

4. Sending warning messages when theft is detected.

To simplify testing and analysis of variables for fuel levels using units of percent $(\%)$ so that it directly compares the original fuel tank and test bench fuel tank. Once the tool is running, data is retrieved directly from the Arduino IDE serial monitor and from the Thingspeak webserver.

Fuel tanks test bench is designed in a scale of 1: 30 to its actual excavator fuel tank. The level sensor used is the same type of sensor but with a slightly different resistance, 8-115 $\Omega$ for dummy sensors and $11-95 \Omega$ for sensors in excavators. In measurements, all parameters in the form of voltage are recorded. When the fuel in the tank full the voltage is $1.86 \mathrm{~V}$. When the fuel in the tank empty the voltage 3.2 Volts.

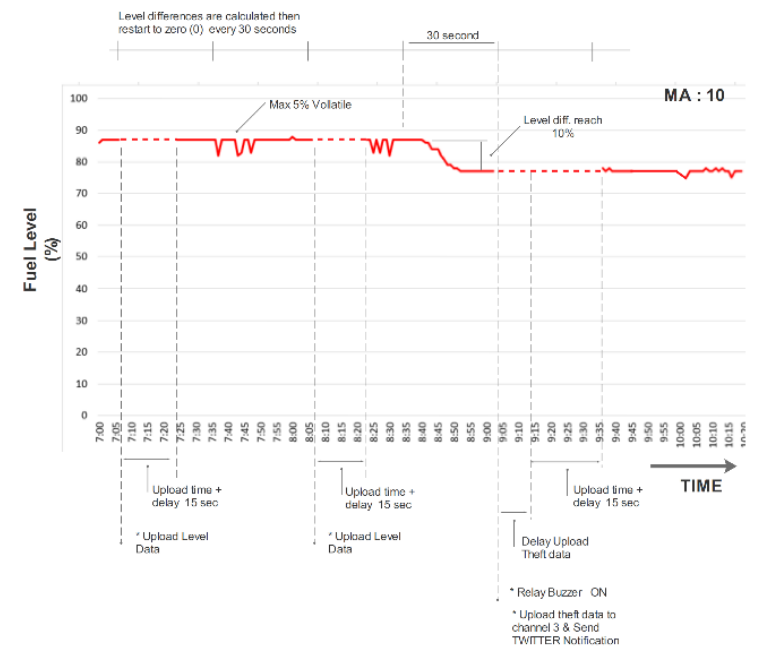

Fig. 10. Level data uploaded from serial display

In this test, several samples have been tried to meet the conditions that must be simulated, i.e.

1. Quick simulation to make sure the program on the controller works according to the program flow that is made. When it fails, the program is immediately repaired and uploaded back to the controller.

2. Simulate the normal level by slowly reducing the fluid in the tank.
3. Simulations of theft directly through the tank by reducing the tank volume quickly is $10 \%$ in 30 second, $2 \%$ in 10 second and $4 \%$ in 10 second.

4. Simulations of extraction from sediment disposal drains with a limit of up to 3 liters is indicated as theft.

By determining the reduction of fuel by $2 \%$ in a period of 10 seconds, there is still the error of determining theft, as shown in Fig. 11.

Thingspeak data log
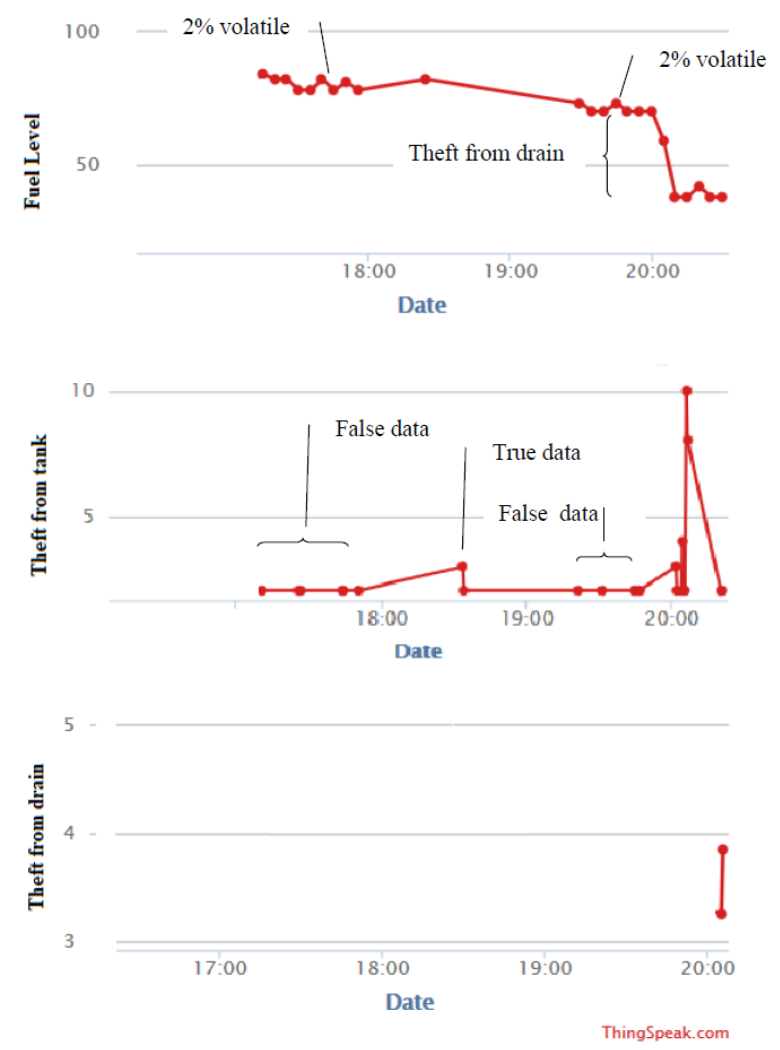

Fig. 11. Fuel data uploaded from Thingspeak webserver with $2 \%$ theft determination

By determining the reduction of fuel by $4 \%$ in a period of 10 seconds, there is no error in determining the theft is shown in Fig. 12.

A small alarm buzzer always sounds when there is fuel flow from the sludge drain and a large buzzer sounds when it is thought theft has occurred and a warning message (Fig. 13 ) is automatically sent via the tweeter with a warning and the amount of fuel stolen.

Data of the amount of fuel and volume of theft can be accessed through the android application (Fig. 14). This application can be developed depending on the number of units to be monitored and also the data display needs. 


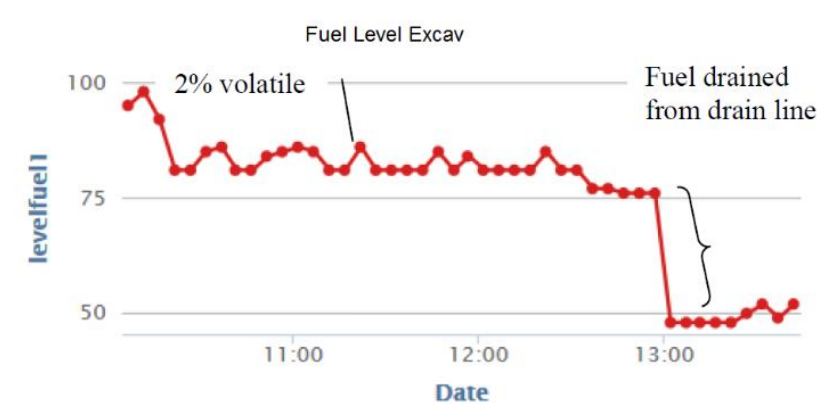

Theft from tank directly

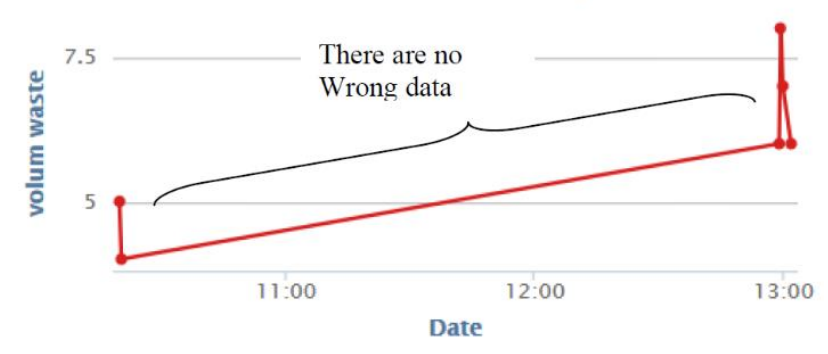

Theft from sewage drain

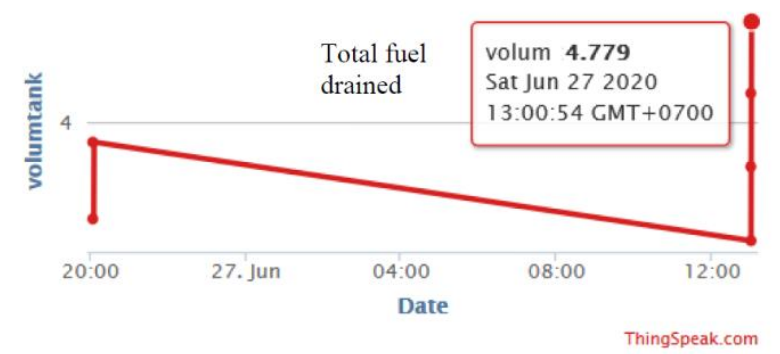

Fig. 12. Fuel data uploaded from Thingspeak webserver with $4 \%$ theft determination.

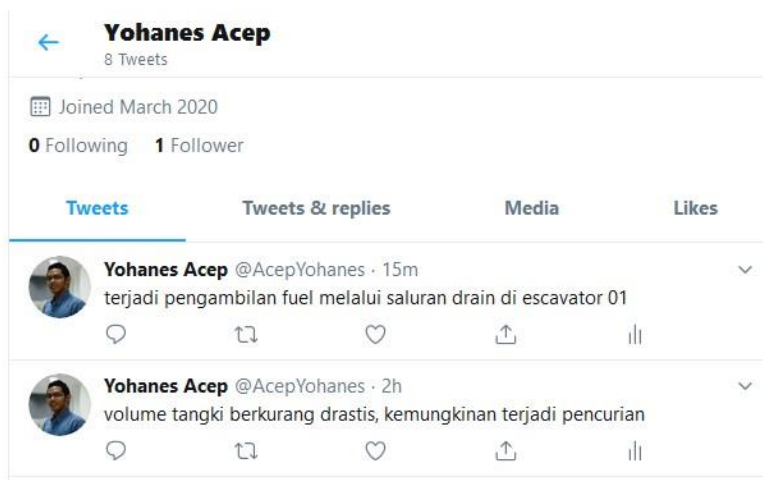

Fig. 13. Tweeter warning message

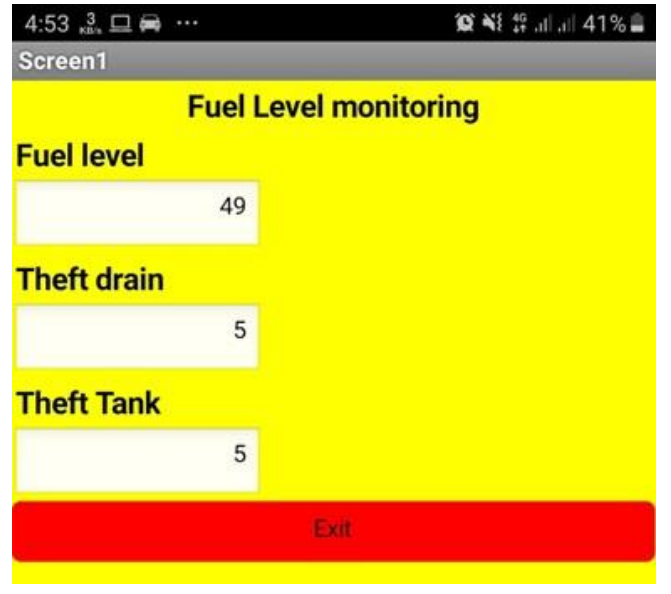

Fig. 14. Application view.

\section{CONCLUSION}

From the experimental results, it can be concluded that the tool that has been developed can be used directly on the Komatsu PC200-8M0 excavator unit using the original sensor from the excavator. The best program configuration is to use moving average 10, Fuel tank theft determination $4 \%$ in 10 second and sewage fuel theft determination 3 liter.

The tool can provide alarm and warning messages to Tweeter. The graphic user interface applications can assess data in Thingspeak webserver .

\section{ACKNOWLEDGMENT}

For their advice and support on this research works, I express my gratitude and thank to Dr. Ir. Hanny J. Berchmans, M.Sc., Dr. Cuk Supriyadi Ali Nandar and all lecturer sin Swiss German University.

\section{REFERENCES}

[1] Komatsu, Shop Manual PC200-8M0, 2016. unpublished.

[2] Komatsu, Operation and Maintenance Manual PC200-8M0, 2016. unpublished.

[3] Komatsu, Part Bookl PC200-8M0, 2016. unpublished.

[4] Komatsu, Komatsu Leaflet PC200-8M0, 2016. unpublished.

[5] Schwartz Macro, Internet of Things With ESP8266. Packt Publishing Ltd: Mumbai, 2016.

[6] MC Measurement Computing, Data Acquisition Handbook. Measurement Computing Corporation: United States of America, 2012.

[7] J. D. Sembiring, H. J. Berchmans, and G. Baskoro. "Fuel filter data monitoring and auto switching at komatsu engine with arduino to improve life cycle time main fuel filter usage," $1^{\text {st }}$ Proceedings of The Conference on Management and Engineering in Industry (CMEI 2019), vol. 1, pp. 9-12, Tangerang, Indonesia, August 2019.

[8] R. Patel, H. Pungalia, and S. Mahajan, "Flow meter and arduino based fuel gauge for automotive vehicles," IOSR Journal of Mechanical and Civil Engineering, 13 (5), pp. 85-92, 2016.

[9] M. Taku, S.Takaichi, O. Yosunori, O. Yukio, and T. Tadashi, "Development of vachile health monitoring system (VHMS/WebCARE) for large size construction machine, Komatsu Technical Report, 48 (150), pp. 15-21, 2002. 